\title{
Risk prediction for 30-day mortality among patients with Clostridium difficile infections: a retrospective cohort study
}

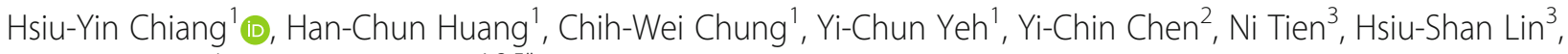
Mao-Wang $\mathrm{Ho}^{4}$ and Chin-Chi Kuo ${ }^{1,2,5^{*}}$

\begin{abstract}
Background: Current guidelines have unsatisfied performance in predicting severe outcomes after Clostridium difficile infection (CDI). Our objectives were to develop a risk prediction model for 30-day mortality and to examine its performance among inpatients with CDI.

Methods: This retrospective cohort study was conducted at China Medical University Hospital, a 2111-bed tertiary medical center in central Taiwan. We included adult inpatients who had a first positive C. difficile culture or toxin assay and had diarrhea as the study population. The main exposure of interest was the biochemical profiles of white blood cell count, serum creatinine (SCr), estimated glomerular filtration rate, blood urea nitrogen (BUN), serum albumin, and glucose. The primary outcome was the 30-day all-cause mortality and the secondary outcome was the length of stay in the intensive care units (ICU) following CDI. A multivariable Cox model and a logistic regression model were developed using clinically relevant and statistically significant variables for 30-day mortality and for length of ICU stay, respectively. A risk scoring system was established by standardizing the coefficients. We compared the performance of our models and the guidelines.

Results: Of 401 patients, 23.4\% died within 30 days. In the multivariable model, malignancy (hazard ratio [HR] = $1.95)$, $\geq 1.5$-fold rise in $\mathrm{SCr}(\mathrm{HR}=2.27)$, BUN-to-SCr ratio $>20(\mathrm{HR}=2.04)$, and increased glucose ( $\geq 193 \mathrm{vs}<142 \mathrm{mg} /$ $\mathrm{dL}, \mathrm{HR}=2.18$ ) were significant predictors of 30-day mortality. For patients who survived the first 30 days of $C D I$, BUN-to-SCr ratio $>20$ (Odds ratio $[\mathrm{OR}]=4.01$ ) was the only significant predictor for prolonged (> 9 days) length of ICU stay following CDI. The Harrell's c statistic of our Cox model for 30-day mortality (0.727) was significantly superior to those of SHEA-IDSA 2010 (0.645), SHEA-IDSA 2018 (0.591), and ECSMID (0.650). Similarly, the conventional $c$ statistic of our logistic regression model for prolonged ICU stay (0.737) was significantly superior to that of the guidelines (SHEA-IDSA 2010, $c=0.600$; SHEA-IDSA 2018, $c=0.634$; ESCMID, $c=0.645$ ). Our risk prediction scoring system for 30-day mortality correctly reclassified 20.7, 32.1, and $47.9 \%$ of patients, respectively.
\end{abstract}

Conclusions: Our model that included novel biomarkers of BUN-to-SCr ratio and glucose have a higher predictive performance of 30-day mortality and prolonged ICU stay following CDI than do the guidelines.

Keywords: Clostridium difficile infection, Mortality, ICU stay, Glucose, BUN-to-SCr ratio

\footnotetext{
* Correspondence: chinchik@gmail.com

${ }^{1}$ Big Data Center, China Medical University Hospital, Taichung 404, Taiwan

${ }^{2}$ Department of Medical Research, Department of Internal Medicine, China

Medical University Hospital, Taichung 404, Taiwan

Full list of author information is available at the end of the article
}

(c) The Author(s). 2019 Open Access This article is distributed under the terms of the Creative Commons Attribution 4.0 International License (http://creativecommons.org/licenses/by/4.0/), which permits unrestricted use, distribution, and reproduction in any medium, provided you give appropriate credit to the original author(s) and the source, provide a link to the Creative Commons license, and indicate if changes were made. The Creative Commons Public Domain Dedication waiver (http://creativecommons.org/publicdomain/zero/1.0/) applies to the data made available in this article, unless otherwise stated. 


\section{Background}

Clostridium difficile infection (CDI) is a critical healthcare-associated infection and accounts for 20-30\% of antibiotic-associated diarrhea [1, 2]. The Antibiotic Resistance Threats in the United States report prioritized C. difficile as an urgent threat because it spreads rapidly and is naturally resistant to many antimicrobials used to treat other infections [3].

Predicting patients with CDI who are at risk of developing severe complications can guide appropriate treatment and follow-up, and in turn, prevent adverse outcomes [4, 5]. SHEA-IDSA 2010 and SHEA-IDSA 2018 clinical practice guidelines for treating CDI recommend using vancomycin or fidaxomicin to treat initial severe CDI $[6,7]$. Two published studies provided evidence that, as high as $31.2-38 \%$ of severe CDI and $56-65 \%$ of severe-complicate CDI were under-treated $[4,5]$. Compared with patients who were treated appropriately, those who were under-treated (according to SHEA-IDSA 2010 guideline) [6] were more likely to have adverse outcomes of all-cause mortality (Crowell's: $7.2 \%$ vs $15.0 \%$; Patel's: $12.9 \%$ vs $43.5 \%)$, CDI-related mortality (Crowell's: $3.8 \%$ vs $7.7 \%$; Patel's: $8.9 \%$ vs $21.7 \%$ ), prolonged CDI-related hospital length of stay (Crowell's: mean 7.5 days vs 9.4 days), or CDI-related ICU transfer (Patel's: $4.8 \%$ vs $17.4 \%)[4,5]$. When patients were stratified by severity (defined by SHEA-IDSA 2010 guideline) [6], patients with severe CDI who were under-treated experienced more complications than those who were appropriately treated (death: $20 \%$ vs $18.5 \%$ for severe CDI; ICU transfer: $20 \%$ vs $7.4 \%$ for severe CDI), although these findings were not statistically significant [5]. Therefore, identification of potentially severe cases of CDI could provide evidence for appropriate treatment and lead to better patient outcomes.

Conventionally, marked leukocytosis, acute rise in serum creatinine $(\mathrm{SCr})$, hypoalbuminemia, and older age are considered to be prognostic factors of severe complications (ie, intensive care unit [ICU] admission, colectomy, or death), according to guidelines developed by the Society for Healthcare Epidemiology of America and the Infectious Disease Society of America (SHEA-IDSA) in 2010 and 2018 and guidelines developed by the European Society of Clinical Microbiology and Infectious Diseases (ESCMID) in 2014 [6-8]. Although these indicators reasonably represent the underlying interactions between infection, immune-inflammatory responses, and malnutrition, their performance in predicting CDI severity is unsatisfactory $[7,9]$.

Other severity indices that included comorbidities (eg, malignancy and renal disease) [10, 11], symptoms (eg, fever, hypotension, septic shock, pseudomembranous colitis, and ascites) [12-14], or antibiotic utilization [15, 16] as severity predictors have been reported to improve risk assessment of CDI severity in inpatients or ICU settings [17]. However, subjective measures, different outcomes (ie, mortality, colectomy, ICU admission, recurrence, or cure rate), and inconsistent CDI diagnostic criteria (eg, without information of diarrhea status) $[9,18]$, compromise the comparability and generalizability of the previous findings [17]. From a pathophysiological perspective, dehydration, a warning sign of severe diarrhea and subsequent hemodynamic instability, should certainly be considered but has never been evaluated as a risk predictor for severe CDI. Blood urea nitrogen (BUN)-to-SCr ratio, which can quantify dehydration and distinguish pre renal kidney injury from intrinsic kidney disease, is a potential predictor for severe CDI.

To address the aforementioned gaps, we conducted this study to develop a new risk prediction model incorporating comorbidities, markers of infection, renal function, dehydration, and serum glucose to predict the risk of 30-day mortality, and to compare the predictive performance of our model and existing guidelines among adult patients with symptomatic CDI.

\section{Methods \\ Data source}

This retrospective cohort study was conducted at China Medical University Hospital (CMUH), a 2111-bed tertiary medical center in Taiwan. The data source was the CMUH-Clinical Research Data Repository (CRDR), which accumulates the single unified views of 2,660,472 patients who had sought care at CMUH between 2003 and 2016. The Institutional Review Board of CMUH approved this study (105-REC3-068 \& 107-REC2-016).

\section{Study population}

Our study included all patients who had first-time positive results of $C$. difficile toxin assay or culture at CMUH between January 1, 2012, and December 31, 2016. The index date was the date when the specimen of positive $C$. difficile result was obtained. We excluded patients who 1) were aged younger than 20 years, 2) were not admitted, or 3) did not have diarrhea (at least 3 loose stools per day or loose stools for at least 3 days during hospitalization) [14, 19]. Data were pulled from the CMUH-CRDR, except for diarrhea status, which was manually reviewed using medical records. The mortality data were obtained by linking to the National Cause of Death Database. Our study population comprised 401 adult inpatients who had incident symptomatic CDI (Fig. 1).

\section{Covariables and outcomes}

C. difficile testing was performed in inpatients at physicians' discretion, except that universal screening was performed in patients who were admitted to the medical ICU during the period between January 1, 2014, and February 28, 2015. Methods of $C$. difficile testing were presented in Additional file 1: Methods. The main 


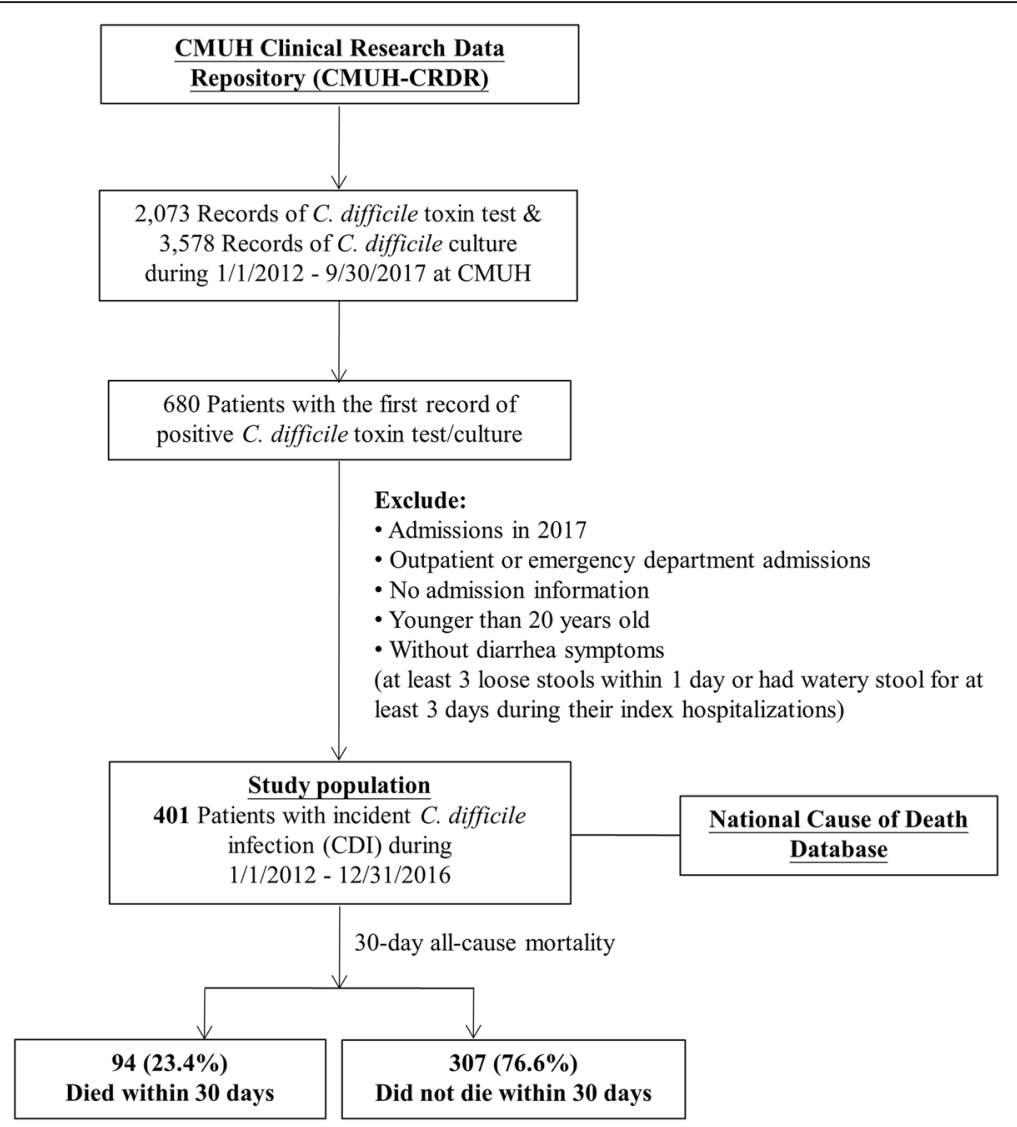

Fig. 1 Flowchart of the selection process of the study population. Abbreviation: CMUH, China Medical University Hospital

exposure of interest was the biochemical profiles of white blood cell count (WBC), SCr, estimated glomerular filtration rate (eGFR) through CKD-EPI equation [20], BUN, serum albumin, and glucose that were measured within -30 to -3 days of the index date (baseline) or measured within \pm 3 days of the index date (index). The definitions of variables are listed in Additional file 1: Figure S1. The primary outcome of interest was the 30day all-cause mortality following the index CDI and the secondary outcome of interest was the length of ICU stay following CDI (for patients who survived the first 30 days of $\mathrm{CDI})$.

\section{Severity predictors from guidelines}

Previous guidelines have provided certain severity predictors for identifying severe cases of CDI. The SHEA-IDSA 2010 criteria for a severe CDI are outlined as follows: having a WBC of $\geq 15,000$ cells $/ \mu \mathrm{L}$ or a 1.5 -fold relative increase in SCr (compared with premorbid level) [6]. The SHEA-IDSA 2018 criteria are presented as follows: having a WBC of $\geq 15,000$ cells $/ \mu \mathrm{L}$ or an index $\mathrm{SCr}$ of $\geq 1.5 \mathrm{mg} / \mathrm{dL}$ $(133 \mu \mathrm{M})$ [7]. The ESCMID 2014 criteria are outlined as follows: being aged $\geq 65$ years, having a WBC of $\geq 15,000$ cells $/ \mu \mathrm{L}$, a serum albumin level of $<3.0 \mathrm{~g} / \mathrm{dL}$, or a $\mathrm{SCr}$ level of $\geq 1.5 \mathrm{mg} / \mathrm{dL}(133 \mu \mathrm{M})$ or a 1.5 -fold relative increase in $\mathrm{SCr}$ [8].

\section{Statistical analyses}

Continuous variables are presented as medians and interquartile ranges (IQR) and were analyzed using the Wilcoxon rank-sum test. Categorical variables are presented as frequency and proportions (\%) and were analyzed using a chi-square test or Fisher's exact test. All analyses were 2 sided, and the significance level was set to 0.05 .

To develop the risk prediction model for 30-day mortality, variables that were significantly associated with 30-day mortality in the univariable analyses (i.e., $P<0.05$ ) and that were clinically relevant were considered in the multivariable Cox proportional hazard model. We categorized the included variables in the multivariable model in the subsequent risk score development. Because of the high proportion of missing values for laboratory tests, we performed multiple imputation using an iterative Markov chain Monte Carlo procedure with 20 imputations and 100 iterations [21]. We used the original data and the data from multiple imputations in separate Cox models for 30day mortality and in separate logistic regression models for prolonged (> 9 days) post-CDI length of ICU stay. We 
compared the performance of our risk prediction model with that of the guidelines by using discrimination measure of Harrell's $c$ statistic for Cox models [22] or conventional $c$ statistic for logistic regression models.

To develop the risk prediction scores, we assigned each independent variable a risk point, which was derived by dividing the beta regression coefficient of each variable by the smallest absolute coefficient and rounding off the quotient to the nearest integer [23]. A severity score was calculated for each patient by summing up the risk points corresponding to the risk factors. We then divided the study population into 2 groups on the basis of their severity scores ( $<29$ vs $\geq 29)$. We compared the performance of our risk prediction scoring system with that of the guidelines by using the reclassification measure of net reclassification index (NRI) [24].

Statistical analysis was performed using SAS version 9.4 (SAS Institute Inc., Cary, NC, USA) and R version 3.0.2 (R Foundation for Statistical Computing, Vienna, Austria) software. All analyses were 2 sided, and the significance level was set to 0.05 .

\section{Results}

\section{Description of patients with C. difficile infections}

Of 401 inpatients with CDI, the mean age was 68.2 years, $59.1 \%$ were men, and $59.3 \%$ had documented fever (Table 1). Positive $C$. difficile toxin test results were detected in $54.1 \%$ of the patients and positive culture results were found in the remaining patients. The median hospital stay was 25 days, $52.9 \%$ were admitted to the ICU, and $23.4 \%$ died within 30 days after the index CDI.

\section{Characteristics associated with 30-day mortality}

Patient who died within 30 days following their CDI were more likely to be older (mean age: 72.5 vs 66.9 years), have malignancies (eg, leukemia and lymphoma; $53.2 \%$ vs $33.9 \%$ ), have fever (70.2\% vs 56.2\%), and have higher Acute Physiology and Chronic Health Evaluation (APACHE) II scores among patients admitted to ICUs prior to CDI (median 18 vs 15), compared with those who survived within 30 days (Table 1).

The biochemical profiles significantly differed between patients who died and those who survived, except for the baseline eGFR. Patients who died had higher levels of WBC (median 13,700 vs 11,700 cells $/ \mu \mathrm{L}$ ), an increased likelihood of having an SCr level 1.5-fold higher than their premorbid level (55.4\% vs $27.8 \%$ ), higher levels of BUN (median 41.0 vs $25.0 \mathrm{mg} / \mathrm{dL}$ ), an increased likelihood of having a BUN-to-SCr ratio of $>20$ (69.4\% vs $40.8 \%)$, lower levels of albumin (median 2.35 vs $2.60 \mathrm{~g} / \mathrm{dL}$ ), and higher levels of glucose (median $192 \mathrm{vs} 158 \mathrm{mg} / \mathrm{dL}$ ).

\section{Risk prediction model for 30-day mortality}

To develop the risk prediction model, we included age > 65 years, malignancy history, index WBC in tertiles, 1.5- fold rise in $\mathrm{SCr}$, albumin $<2.5 \mathrm{~g} / \mathrm{dL}$, BUN-to- $\mathrm{SCr}$ ratio $>$ 20, and glucose in tertiles in a Cox model (Fig. 2). The results obtained for the original and imputed data were similar. Malignancy (hazard ratio $[\mathrm{HR}]=1.95 ;$; $5 \%$ confidence interval $[\mathrm{CI}]=1.28,2.95)$, rise in $\mathrm{SCr}(\mathrm{HR}=2.27$, $95 \% \mathrm{CI}=1.44,3.95), \mathrm{BUN}-$ to- $\mathrm{SCr}$ ratio $>20(\mathrm{HR}=2.04$, $95 \% \mathrm{CI}=1.28,3.24$ ), and glucose level $\geq 193 \mathrm{mg} / \mathrm{dL}$ (reference: $<142 \mathrm{mg} / \mathrm{dL}, \mathrm{HR}=2.18,95 \% \mathrm{CI}=1.17,4.05$ ) were significantly associated with 30-day mortality when imputed data were used. The discrimination performance of our model (Harrell's $c$ statistic $=0.727 ; 95 \% \mathrm{CI}=$ $0.672,0.782)$ was significantly superior to that of the model using severity indicators stated in the SHEAIDSA 2010 ( $c$ statistic $=0.645 ; 95 \% \mathrm{CI}=0.588,0.702)$, SHEA-IDSA 2018 (c statistic $=0.591 ; 95 \% \mathrm{CI}=0.537$, 0.644 ), and the ESCMID guidelines ( $c$ statistic $=0.650$; $95 \% \mathrm{CI}=0.594,0.711)$ (Table 2).

\section{Risk prediction scoring system for 30-day mortality}

To develop a risk prediction scoring system, we assigned each risk predictor a risk point (Table 3). Patients with a risk score of $\geq 29$ were considered to be at a higher risk ( $10 \%$ or higher) of 30 -day mortality. Compared with the SHEA-IDSA 2010, SHEA-IDSA 2018, and ESCMID guidelines, our scoring system reclassified 20.7, 32.1, and $47.9 \%$ of the CDI patients into the correct risk category, respectively (Additional file 1: Table S1).

\section{Risk prediction model for prolonged length of ICU stay following CDI}

Of 307 patients who survived the first 30 days following $\mathrm{CDI}$, the mean length of ICU stay following CDI was 9.8 days (median: 0 days; interquartile range, $0-9$ days). We used the 3rd quartile (9 days) as the cut-off for prolonged post-CDI length of ICU stay in the multivariable logistic regression analysis.

We evaluated the performance of our risk prediction model in predicting post-CDI length of ICU stay $>9$ days (Table 4). BUN-to-SCr ratio was the only significant and strong predictor for prolonged length of ICU stay following CDI (imputed data: adjusted OR, 4.01; 95\% CI, 2.197.33). The discrimination performance of our prediction model was moderate (imputed data: $c$ statistic, $0.737 ; 95 \%$ CI, 0.671-0.804), and was superior to the discrimination performance of SHEA-IDSA 2010 ( $c$ statistic, 0.600; 95\% CI, 0.527-0.673), SHEA-IDSA 2018 ( $c$ statistic, 0.634; 95\% CI, 0.564-0.704), and ESCMID ( $c$ statistic, $0.645 ; 95 \% \mathrm{CI}$, 0.573-0.718) (Table 5).

\section{Discussion}

This is the first epidemiological study to investigate predictors for the severe outcome of CDI in Asia [25]. Our risk prediction model included age $>65$ years, malignancy history, WBC in tertiles, 1.5 -fold rise in $\mathrm{SCr}$, 
Table 1 Baseline demographic and clinical characteristics of adult inpatients with Clostridium difficile infections (CDI)

\begin{tabular}{|c|c|c|c|c|c|c|c|}
\hline \multirow[t]{2}{*}{ Variables $^{a}$} & \multirow{2}{*}{\multicolumn{2}{|c|}{ Total $(N=401)$}} & \multicolumn{4}{|c|}{ 30-Day Mortality } & \multirow{2}{*}{$\begin{array}{l}p^{-} \\
\text {value }^{a}\end{array}$} \\
\hline & & & \multicolumn{2}{|c|}{ Died $(N=94)$} & \multicolumn{2}{|c|}{ Did not die $(N=307)$} & \\
\hline \multicolumn{8}{|l|}{ Age at index date, years } \\
\hline Mean (standard deviation) & 68.2 & 15.8 & 72.5 & 13.2 & 66.9 & 16.4 & $0.001^{b}$ \\
\hline$\geq 65$ years old & 234 & $58.4 \%$ & 63 & $67.0 \%$ & 171 & $55.7 \%$ & 0.051 \\
\hline Male & 237 & $59.1 \%$ & 59 & $62.8 \%$ & 178 & $58.0 \%$ & 0.409 \\
\hline \multicolumn{8}{|l|}{ Comorbidity within 1 year prior ${ }^{c}$} \\
\hline Diabetes mellitus & 201 & $50.1 \%$ & 50 & $53.2 \%$ & 151 & $49.2 \%$ & 0.497 \\
\hline Renal disease & 158 & $39.4 \%$ & 35 & $37.2 \%$ & 123 & $40.1 \%$ & 0.623 \\
\hline Inflammatory bowel disease & 6 & $1.5 \%$ & 1 & $1.1 \%$ & 5 & $1.6 \%$ & $0.372^{b}$ \\
\hline Malignancy & 154 & $38.4 \%$ & 50 & $53.2 \%$ & 104 & $33.9 \%$ & 0.001 \\
\hline Hospital admission within 90 days prior & 182 & $45.4 \%$ & 49 & $52.1 \%$ & 133 & $43.3 \%$ & 0.134 \\
\hline \multicolumn{8}{|l|}{ Antibiotic use within 30 days prior } \\
\hline Cephalosporins & 170 & $42.4 \%$ & 39 & $41.5 \%$ & 131 & $42.7 \%$ & 0.839 \\
\hline Fluoroquinolones & 81 & $20.2 \%$ & 20 & $21.3 \%$ & 61 & $19.9 \%$ & 0.766 \\
\hline Carbapenems & 100 & $24.9 \%$ & 25 & $26.6 \%$ & 75 & $24.4 \%$ & 0.671 \\
\hline Anti-peptic ulcer agents $^{d}$ & 296 & $73.8 \%$ & 68 & $72.3 \%$ & 228 & $74.3 \%$ & 0.710 \\
\hline APACHE II score prior to CDI ${ }^{e}$ & 15.0 & $(10.0,20.0)$ & 18.0 & $(11.0,21.0)$ & 15.0 & $(10.0,20.0)$ & 0.036 \\
\hline Fever $\left(\geq 38^{\circ} \mathrm{C}\right)$ at index $\mathrm{CDI}$ & 223 & $59.3 \%$ & 59 & $70.2 \%$ & 164 & $56.2 \%$ & 0.021 \\
\hline Anti-diarrhea medications ${ }^{f}$ & 225 & $56.1 \%$ & 51 & $54.3 \%$ & 174 & $56.7 \%$ & 0.679 \\
\hline \multicolumn{8}{|l|}{ Stool routine } \\
\hline Presence of mucus & 52 & $15.6 \%$ & 10 & $14.1 \%$ & 42 & $16.0 \%$ & 0.689 \\
\hline Positive for red blood cell & 121 & $36.3 \%$ & 26 & $36.6 \%$ & 95 & $36.3 \%$ & 0.955 \\
\hline Positive for WBC & 115 & $34.5 \%$ & 24 & $33.8 \%$ & 91 & $34.7 \%$ & 0.884 \\
\hline \multicolumn{8}{|l|}{ C. difficile toxin or culture } \\
\hline Toxin test ${ }^{9}$ & 217 & $54.1 \%$ & 49 & $52.1 \%$ & 168 & $54.7 \%$ & 0.659 \\
\hline Culture only & 184 & $45.9 \%$ & 45 & $47.9 \%$ & 139 & $45.3 \%$ & \\
\hline \multicolumn{8}{|l|}{ Biochemical profiles at index $\mathrm{CDI}^{\mathrm{h}}$} \\
\hline White blood cell count (WBC), cells $/ \mathrm{mm}^{3}$ & 12,000 & $(8300,17,100)$ & 13,700 & $(8600,20,900)$ & 11,700 & $(8100,16,400)$ & 0.014 \\
\hline First tertile: $<9440$ & 129 & $33.0 \%$ & 27 & $28.7 \%$ & 102 & $34.3 \%$ & 0.017 \\
\hline Second tertile: 9440 to $<14,600$ & 126 & $32.2 \%$ & 23 & $24.5 \%$ & 103 & $34.7 \%$ & \\
\hline Third tertile: $\geq 14,600$ & 136 & $34.8 \%$ & 44 & $46.8 \%$ & 92 & $31.0 \%$ & \\
\hline WBC $>15,000$ & 126 & $32.2 \%$ & 41 & $43.6 \%$ & 85 & $28.6 \%$ & 0.007 \\
\hline \multicolumn{8}{|l|}{ Serum creatinine $(\mathrm{SCr}), \mathrm{mg} / \mathrm{dL}$} \\
\hline Premorbid SCri & 1.01 & $(0.67,2.05)$ & 0.97 & $(0.60,1.56)$ & 1.03 & $(0.69,2.30)$ & 0.392 \\
\hline Index SCr & 1.41 & $(0.81,3.74)$ & 1.64 & $(0.90,3.66)$ & 1.34 & $(0.76,3.82)$ & 0.224 \\
\hline \multicolumn{8}{|l|}{ Rise in SCr level } \\
\hline$\geq 1.5$-fold & 113 & $34.9 \%$ & 46 & $55.4 \%$ & 67 & $27.8 \%$ & $<0.001$ \\
\hline$\geq 1.5045 \mathrm{mg} / \mathrm{dL}$ & 56 & $17.3 \%$ & 19 & $22.9 \%$ & 37 & $15.4 \%$ & 0.1172 \\
\hline$\geq 1.5$-fold or $\geq 1.5045 \mathrm{mg} / \mathrm{dL}$ & 123 & $38.0 \%$ & 48 & $57.8 \%$ & 75 & $31.1 \%$ & $<0.001$ \\
\hline eGFR (CKD-EPI) $)^{j} \mathrm{ml} / \mathrm{min} / 1.73 \mathrm{~m}^{2}$ & 51.4 & $(17.3,91.0)$ & 47.3 & $(16.7,88.3)$ & 52.5 & $(17.6,92.5)$ & 0.623 \\
\hline $\mathrm{BUN}, \mathrm{mg} / \mathrm{dL}$ & 29.0 & $(14.0,60.0)$ & 41.0 & $(21.0,85.0)$ & 25.0 & $(13.0,52.5)$ & $<0.001$ \\
\hline First tertile: $<17$ & 110 & $30.8 \%$ & 14 & $16.5 \%$ & 96 & $35.3 \%$ & 0.004 \\
\hline Second tertile: 17 to $<44$ & 121 & $33.9 \%$ & 33 & $38.8 \%$ & 88 & $32.4 \%$ & \\
\hline Third tertile: $\geq 44$ & 126 & $35.3 \%$ & 38 & $44.7 \%$ & 88 & $32.4 \%$ & \\
\hline
\end{tabular}


Table 1 Baseline demographic and clinical characteristics of adult inpatients with Clostridium difficile infections (CDI) (Continued)

\begin{tabular}{|c|c|c|c|c|c|c|c|}
\hline \multirow{3}{*}{$\begin{array}{c}\text { Variables }^{a} \\
\text { BUN > } 26\end{array}$} & \multirow{2}{*}{\multicolumn{2}{|c|}{ Total $(N=401)$}} & \multicolumn{4}{|c|}{ 30-Day Mortality } & \multirow{3}{*}{$\frac{p^{p-}}{\text { value }^{a}}$} \\
\hline & & & \multicolumn{2}{|c|}{ Died $(N=94)$} & \multicolumn{2}{|c|}{ Did not die $(N=307)$} & \\
\hline & 188 & $52.7 \%$ & 55 & $64.7 \%$ & 133 & $48.9 \%$ & \\
\hline BUN-to-SCr ratio & 18.8 & $(12.2,30.1)$ & 26.1 & $(17.6,36.8)$ & 16.8 & $(11.1,27.3)$ & $<0.001$ \\
\hline Index BUN-to-SCr > 20 & 170 & $47.6 \%$ & 59 & $69.4 \%$ & 111 & $40.8 \%$ & $<0.001$ \\
\hline Albumin, $\mathrm{g} / \mathrm{dL}$ & 2.50 & $(2.20,2.90)$ & 2.35 & $(2.00,2.80)$ & 2.60 & $(2.20,3.00)$ & 0.003 \\
\hline Albumin $<2.5$ & 89 & $44.3 \%$ & 33 & $56.9 \%$ & 56 & $39.2 \%$ & 0.022 \\
\hline Albumin $<3$ & 155 & $77.1 \%$ & 50 & $86.2 \%$ & 105 & $73.4 \%$ & 0.051 \\
\hline Serum glucose, mg/dL & 162 & $(129,222)$ & 192 & $(151,232)$ & 158 & $(127,208)$ & 0.002 \\
\hline First tertile: $<142$ & 107 & $32.7 \%$ & 13 & $16.9 \%$ & 94 & $37.6 \%$ & 0.001 \\
\hline Second tertile: 142 to $<193$ & 108 & $33.0 \%$ & 26 & $33.8 \%$ & 82 & $32.8 \%$ & \\
\hline Third tertile: $\geq 193$ & 112 & $34.3 \%$ & 38 & $49.4 \%$ & 74 & $29.6 \%$ & \\
\hline
\end{tabular}

Abbreviations: APACHE Acute Physiology and Chronic Health Evaluation, BUN blood urea nitrogen level, CDI C. difficile infections, CI confidence interval, eGFR estimated Glomerular filtration rate, $H R$ hazard ratio, IQR interquartile range, $S C r$ serum creatinine, WBC white blood cell count

${ }^{a}$ Continuous variables were presented as median and IQRs and analyzed using Wilcoxon rank-sum test, if not otherwise indicated. Categorical variables were presented as frequency and proportion (\%) and analyzed using chi-square test, if not otherwise indicated. $P$-values that were $<0.05$ are shown in bold. ${ }^{\mathrm{b}} \mathrm{Mean}$ age and the proportion of inflammatory bowel disease were analyzed using two-sample t-test and Fisher's exact test, respectively.

'Diabetes mellitus was defined according to the patients' ICD-9-CM diagnosis codes and the use of glucose-lowering agents. Renal disease, inflammatory bowel disease, and malignancy were defined using the ICD-9-CM diagnosis codes.

dUse of anti-peptic ulcer agents of proton-pump inhibitors and histamine-2 receptor antagonists within 0 to 14 days of the index CDI.

${ }^{\mathrm{e}} \mathrm{APACHE}$ II score was only available for patients admitted to intensive care units $(N=211)$.

fUse of anti-diarrhea medications or probiotics within 0 to 14 days of the index CDI.

Included 158 patients (39.4\%) with positive toxin genes test and 59 patients (14.7\%) with positive $C$. difficile toxin enzyme immunoassay test.

hWe obtained the maximum WBC, maximum index SCr, closest BUN, minimum albumin, and closest glucose values that were measured within -3 to +3 days of the index CDI.

'For premorbid $\mathrm{SCr}$, we obtained the minimum $\mathrm{SCr}$ that were measured within -30 to -4 days of the index CDI.

jeGFR was estimated by CKD-EPI equation (Levey 2009).

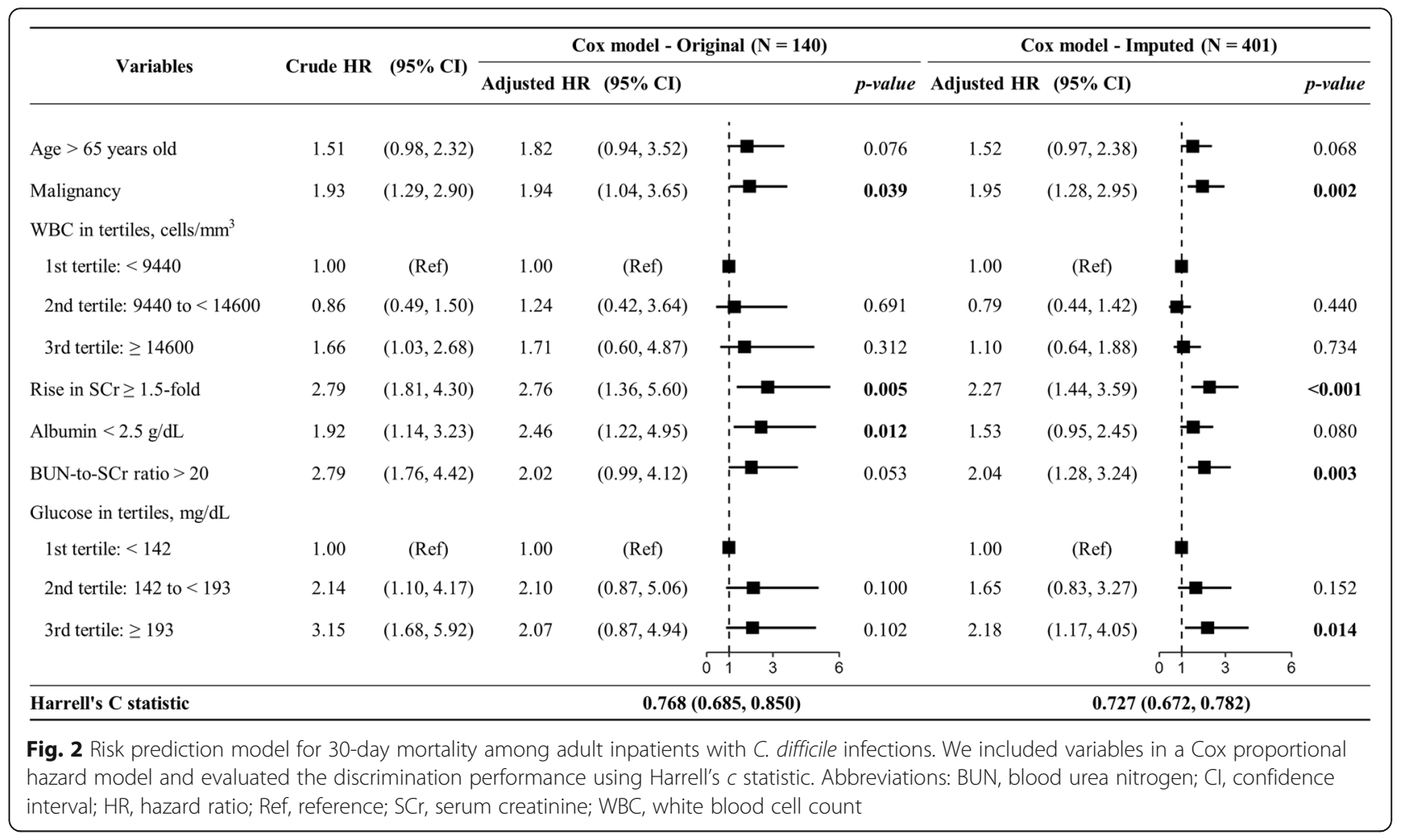


Table 2 Discrimination performance of published guidelines for 30-day mortality among adult inpatients with C. difficile infections ${ }^{a}$

\begin{tabular}{|c|c|c|c|c|c|c|c|c|c|c|c|c|}
\hline \multirow[t]{3}{*}{ Variables } & \multicolumn{4}{|c|}{ SHEA-IDSA $(2010)^{b}$} & \multicolumn{4}{|c|}{ SHEA-IDSA (2018) } & \multicolumn{4}{|l|}{ ESCMID $(2014)^{c}$} \\
\hline & \multicolumn{2}{|l|}{ Original $(N=322)$} & \multicolumn{2}{|c|}{ Imputed ( $N=401)$} & \multicolumn{2}{|l|}{ Original $(N=374)$} & \multicolumn{2}{|c|}{ Imputed $(N=401)$} & \multicolumn{2}{|c|}{ Original $(N=165)$} & \multicolumn{2}{|c|}{ Imputed $(\mathrm{N}=401)$} \\
\hline & aHR $(95 \% \mathrm{Cl})$ & $\begin{array}{l}p- \\
\text { value }\end{array}$ & aHR (95\% Cl) & $\begin{array}{l}p- \\
\text { value }\end{array}$ & aHR (95\% Cl) & $\begin{array}{l}p^{-} \\
\text {value }\end{array}$ & aHR $(95 \% \mathrm{Cl})$ & $\begin{array}{l}p \text { - } \\
\text { value }\end{array}$ & aHR (95\% Cl) & $\begin{array}{l}p \text { - } \\
\text { value }\end{array}$ & aHR $(95 \% \mathrm{Cl})$ & $\begin{array}{l}p- \\
\text { value }\end{array}$ \\
\hline Age $>65$ years old & - & - & - & - & - & - & - & - & $1.44(0.84,2.47)$ & 0.185 & $1.41(0.91,2.17)$ & 0.124 \\
\hline $\begin{array}{l}\text { WBC }>15,000 \text { cells/ } \\
\mathrm{mm}^{3}\end{array}$ & $1.44(0.92,2.24)$ & 0.110 & $1.43(0.92,2.24)$ & 0.113 & $1.72(1.13,2.61)$ & 0.012 & $1.69(1.11,2.56)$ & 0.013 & $1.91(1.12,3.27)$ & 0.018 & $1.51(1.00,2.29)$ & 0.053 \\
\hline Rise in $\mathrm{SCr} \geq 1.5$-fold & $2.55(1.64,3.98)$ & $\begin{array}{l}< \\
0.0001\end{array}$ & $2.58(1.65,4.03)$ & $\begin{array}{l}< \\
0.0001\end{array}$ & - & - & - & - & - & - & - & - \\
\hline $\mathrm{SCr} \geq 1.5045 \mathrm{mg} / \mathrm{dL}$ & - & - & - & - & $1.27(0.84,1.93)$ & 0.265 & $1.35(0.89,2.04)$ & 0.157 & - & - & - & - \\
\hline $\begin{array}{l}\text { Rise in } \mathrm{SCr} \geq 1.5 \text {-fold } \\
\text { or } \geq 1.5045 \mathrm{mg} / \mathrm{dL}\end{array}$ & - & - & - & - & - & - & - & - & $1.40(0.77,2.54)$ & 0.268 & $2.23(1.37,3.61)$ & 0.001 \\
\hline Albumin $<3 \mathrm{~g} / \mathrm{dL}$ & - & - & - & - & - & - & - & - & $1.93(0.91,4.08)$ & 0.085 & $1.60(0.83,3.10)$ & 0.159 \\
\hline c statistic (95\% Cl) & \multicolumn{2}{|c|}{$0.644(0.587,0.701)$} & \multicolumn{2}{|c|}{$0.645(0.588,0.702)^{d}$} & \multicolumn{2}{|c|}{$0.587(0.533,0.641)$} & \multicolumn{2}{|c|}{$0.591(0.537,0.644)^{d}$} & \multicolumn{2}{|c|}{$0.640(0.571,0.709)$} & \multicolumn{2}{|c|}{$0.650(0.594,0.706)^{d}$} \\
\hline
\end{tabular}

Abbreviations: aHR adjusted hazard ratio, CDI C. difficile infections, $\mathrm{Cl}$ confidence interval, $\mathrm{SCr}$ serum creatinine, WBC white blood cell count

a We included the variables in separate Cox proportional hazard models and evaluated the discrimination performance of these models using Harrell's $c$ statistic.

${ }^{\mathrm{b}}$ The Society of Hospital Epidemiology of America (SHEA) and the Infectious Disease Society of America (IDSA) jointly published the clinical practice guidelines for CDI in 2010 and updated in 2018 (Cohen 2010; McDonald 2018).

'The European Society of Clinical Microbiology and Infectious Diseases (ESCMID) published the treatment guideline for CDI in 2014 (Debast 2014 ).

${ }^{d}$ The discrimination performance of these models was significantly lower than that of our prediction model (Harrell's $c$ statistic $\left.=0.727 ; 95 \% \mathrm{Cl}=0.672,0.782\right)$.

albumin $<2.5 \mathrm{~g} / \mathrm{dL}$, BUN-to-SCr ratio $>20$, and serum glucose in tertiles, where BUN-to-SCr ratio and glucose have not been indicated in prior studies. Our risk prediction model and risk prediction scoring system performed superior to current guidelines in predicting 30-day mortality and prolonged length of ICU stay following CDI.

Published guidelines in the US (SHEA-IDSA 2010 and 2018) [6,7] and Europe (ECSMID 2014) [8] and recently developed severity indices, such as the Zar [26], Bauer [19], ATLAS [15], Velazquez-Gomez [14], or Gomez-Simmonds [27] scoring systems, have attempted to establish valid criteria for predicting the severity of CDI. Nonetheless, guidelines are based on expert opinions or systematic reviews and the definitions of severe CDI and its treatment outcomes evaluated in other studies have varied. For example, Zar et al. assessed both cure rate and relapse [26]; Bauer et al. evaluated treatment failure and recurrence [19]; and ATLAS evaluated cure rate, and its findings were validated in another cohort for mortality and colectomy $[15,28]$. Increased levels of WBC $(\geq 15,000$ or 30,000 cells $/ \mu \mathrm{L})$ and rise in $\mathrm{SCr}$ (1.5-fold high than the premorbid level or absolute value of $1.5 \mathrm{mg} / \mathrm{dL}$ ), which indicate immune reaction and renal function, are the most common markers between the aforementioned severity criteria $[6,7,15,19]$. Hypoalbuminemia $(<2.5$ or $<3 \mathrm{mg} / \mathrm{dL})$, a malnutrition

Table 3 Risk prediction model for 30-day mortality among adult inpatients with C. difficile infections and the risk points

\begin{tabular}{|c|c|c|}
\hline Variables & Regression coefficients ( $\beta \mathrm{s}$ ) & Risk point $^{a}$ \\
\hline Age $>65$ years old & 0.4179 & 4 \\
\hline Malignancy & 0.6656 & 7 \\
\hline \multicolumn{3}{|l|}{ WBC in tertiles, cells $/ \mathrm{mm}^{3}$} \\
\hline First tertile: < 9440 & Reference & 0 \\
\hline Second tertile: 9440 to $<14,600$ & -0.2299 & -2 \\
\hline Third tertile: $\geq 14,600$ & 0.0930 & 1 \\
\hline Rise in $\mathrm{SCr} \geq 1.5$-fold & 0.8212 & 9 \\
\hline Albumin $<2.5 \mathrm{~g} / \mathrm{dL}$ & 0.4226 & 5 \\
\hline \multicolumn{3}{|l|}{ Glucose in tertiles, mg/dL } \\
\hline First tertile: $<142$ & Reference & 0 \\
\hline Second tertile: 142 to $<193$ & 0.4993 & 5 \\
\hline Third tertile: $\geq 193$ & 0.7784 & 8 \\
\hline BUN-to-SCr ratio > 20 & 0.7119 & 8 \\
\hline
\end{tabular}

Abbreviations: BUN blood urea nitrogen, $\mathrm{SCr}$ serum creatinine, $W B C$ white blood cell count

${ }^{a}$ We assigned each variable a risk point by dividing the corresponding regression coefficient by the absolute smallest coefficient (i.e., 0.0930 ) and rounding it to the nearest integer. 
Table 4 Risk prediction model for prolonged (>9 days) length of ICU stay following C. difficile infections (CDI) among adult inpatients with CDI who survived the first 30 days following $C D I(N=307)^{a}$

\begin{tabular}{|c|c|c|c|c|c|c|}
\hline \multirow[t]{2}{*}{ Variables } & \multirow[t]{2}{*}{$\begin{array}{l}\text { Crude OR } \\
(95 \% \mathrm{Cl})\end{array}$} & \multirow[t]{2}{*}{$\begin{array}{l}P \text { - } \\
\text { value }\end{array}$} & $\begin{array}{l}\text { Logistic regression model - Original } \\
(N=99)\end{array}$ & \multirow[t]{2}{*}{$\begin{array}{l}P \text { - } \\
\text { value }\end{array}$} & $\begin{array}{l}\text { Logistic regression model - Imputed } \\
(N=307)\end{array}$ & \multirow[t]{2}{*}{$\begin{array}{l}P \text { - } \\
\text { value }\end{array}$} \\
\hline & & & Adjusted OR (95\% Cl) & & Adjusted OR (95\% Cl) & \\
\hline Age $>65$ years old & $1.51(0.88,2.57)$ & 0.133 & $1.37(0.56,3.36)$ & 0.492 & $1.28(0.72,2.30)$ & 0.400 \\
\hline Malignancy & $0.57(0.32,1.03)$ & 0.061 & $0.60(0.23,1.60)$ & 0.310 & $0.54(0.29,1.03)$ & 0.061 \\
\hline \multicolumn{7}{|l|}{ WBC in tertiles, cells $/ \mathrm{mm}^{3}$} \\
\hline 1st tertile: $<9440$ & 1.00 (Ref) & & 1.00 (Ref) & & 1.00 (Ref) & \\
\hline $\begin{array}{l}\text { 2nd tertile: } 9440 \text { to }< \\
14,600\end{array}$ & $1.33(0.68,2.61)$ & 0.412 & $1.17(0.37,3.74)$ & 0.786 & $1.19(0.57,2.52)$ & 0.640 \\
\hline 3rd tertile: $\geq 14,600$ & $2.33(1.21,4.50)$ & 0.012 & $1.21(0.36,4.01)$ & 0.756 & $1.76(0.84,3.69)$ & 0.132 \\
\hline Rise in $\mathrm{SCr} \geq 1.5$-fold & $1.48(0.79,2.76)$ & 0.217 & $2.40(0.92,6.26)$ & 0.073 & $1.34(0.69,2.59)$ & 0.393 \\
\hline Albumin $<2.5 \mathrm{~g} / \mathrm{dL}$ & $2.22(1.08,4.54)$ & 0.030 & $1.89(0.72,4.95)$ & 0.195 & $1.36(0.66,2.82)$ & 0.400 \\
\hline BUN-to-SCr ratio > 20 & $4.74(2.66,8.46)$ & $\begin{array}{l}< \\
0.001\end{array}$ & $3.81(1.51,9.58)$ & 0.005 & $4.01(2.19,7.33)$ & $\begin{array}{l}< \\
0.001\end{array}$ \\
\hline \multicolumn{7}{|l|}{ Glucose tertiles, mg/dL } \\
\hline 1st tertile: $<142$ & 1.00 (Ref) & & 1.00 (Ref) & & 1.00 (Ref) & \\
\hline 2nd tertile: 142 to $<193$ & $1.61(0.83,3.12)$ & 0.161 & $1.41(0.46,4.33)$ & 0.545 & $1.28(0.72,2.30)$ & 0.480 \\
\hline 3rd tertile: $\geq 193$ & $1.57(0.79,3.11)$ & 0.194 & $0.87(0.28,2.72)$ & 0.812 & $0.54(0.29,1.03)$ & 0.618 \\
\hline C statistic (95\% Cl) & & & $0.741(0.639,0.844)$ & & $0.737(0.671,0.804)$ & \\
\hline
\end{tabular}

Abbreviations: BUN blood urea nitrogen, $C$ confidence interval, $O R$ odds ratio, Ref reference, $S C r$ serum creatinine, $W B C$ white blood cell count

${ }^{a}$ We included variables in a logistic regression model and evaluated the discrimination performance using conventional $c$ statistic.

marker, is another commonly marker for severe CDI $[8$, $14,26,27]$.

Other predictors of poor CDI outcomes that have been reported included: older age [26], systemic antibiotic use, underlying illnesses, altered mental status [14], physical findings (eg, fever, hypotension [14], tachycardia [14], abdominal pain or distention, and septic shock
[27]), pseudomembranous colitis [14, 26, 27], ICU admission [14, 26], toxic megacolon, and colectomy [27]. However, ICU admission and CDI-related complications should not be used as prognostic predictors because these events are outcomes of severe CDI.

Our severity predictive model had significantly higher discrimination power than did the existing guidelines in

Table 5 Discrimination performance of published guidelines for prolonged (> 9 days) length of ICU stay following C. difficile infections (CDI) among adult inpatients with CDI who survived the first 30 days following $C D I(N=307)^{\text {a }}$

\begin{tabular}{|c|c|c|c|c|c|c|c|c|c|c|c|c|}
\hline \multirow[t]{3}{*}{ Variables } & \multicolumn{4}{|c|}{ SHEA-IDSA $(2010)^{b}$} & \multicolumn{4}{|c|}{ SHEA-IDSA (2018) } & \multicolumn{4}{|l|}{ ESCMID $(2014)^{c}$} \\
\hline & \multicolumn{2}{|l|}{ Original $(N=239)$} & \multicolumn{2}{|c|}{ Imputed $(N=307)$} & \multicolumn{2}{|l|}{ Original $(N=283)$} & \multicolumn{2}{|l|}{ Imputed $(N=307)$} & \multicolumn{2}{|l|}{ Original $(N=143)$} & \multicolumn{2}{|l|}{ Imputed $(\mathrm{N}=307)$} \\
\hline & aOR $(95 \% \mathrm{Cl})$ & $\begin{array}{l}p^{-} \\
\text {value }\end{array}$ & $\mathrm{aOR}(95 \% \mathrm{Cl})$ & $\begin{array}{l}p^{-} \\
\text {value }\end{array}$ & aOR $(95 \% \mathrm{Cl})$ & $\begin{array}{l}p^{-} \\
\text {value }\end{array}$ & aOR $(95 \% \mathrm{Cl})$ & $\begin{array}{l}p^{-} \\
\text {value }\end{array}$ & aOR (95\% Cl) & $\begin{array}{l}p- \\
\text { value }\end{array}$ & $\mathrm{aOR}(95 \% \mathrm{Cl})$ & $\begin{array}{l}p^{-} \\
\text {value }\end{array}$ \\
\hline Age $>65$ years old & - & - & - & - & - & - & - & - & $1.25(0.60,2.60)$ & 0.549 & $1.45(0.84,2.51)$ & 0.182 \\
\hline $\begin{array}{l}\text { WBC }>15,000 \text { cells/ } \\
\mathrm{mm}^{3}\end{array}$ & $1.96(1.06,3.64)$ & 0.033 & $2.19(1.25,3.83)$ & 0.006 & $2.26(1.28,3.99)$ & 0.005 & $2.10(1.20,3.67)$ & 0.009 & $1.80(0.84,3.85)$ & 0.129 & $2.11(1.20,3.70)$ & 0.010 \\
\hline Rise in $\mathrm{SCr} \geq 1.5$-fold & $1.31(0.69,2.49)$ & 0.403 & $1.30(0.70,2.40)$ & 0.411 & - & - & - & - & - & - & - & - \\
\hline $\mathrm{SCr} \geq 1.5045 \mathrm{mg} / \mathrm{dL}$ & - & - & - & - & $1.91(1.10,3.31)$ & 0.022 & $1.84(1.07,3.16)$ & 0.026 & - & - & - & - \\
\hline $\begin{array}{l}\text { Rise in } \mathrm{SCr} \geq 1.5 \text {-fold } \\
\text { or } \geq 1.5045 \mathrm{mg} / \mathrm{dL}\end{array}$ & - & - & - & - & - & - & - & - & $2.38(1.08,5.23)$ & 0.031 & $1.74(0.98,3.09)$ & 0.057 \\
\hline Albumin $<3 \mathrm{~g} / \mathrm{dL}$ & - & - & - & - & - & - & - & - & $1.74(0.72,4.17)$ & 0.219 & $1.29(0.58,2.85)$ & 0.529 \\
\hline C statistic (95\% Cl) & \multicolumn{2}{|c|}{$0.591(0.513,0.670)$} & \multicolumn{2}{|c|}{$0.600(0.527,0.673)^{d}$} & \multicolumn{2}{|c|}{$0.643(0.572,0.714)$} & \multicolumn{2}{|c|}{$0.634(0.564,0.704)^{d}$} & \multicolumn{2}{|c|}{$0.657(0.561,0.754)$} & \multicolumn{2}{|c|}{$0.645(0.573,0.718)^{d}$} \\
\hline
\end{tabular}


predicting 30-day mortality. Our scoring system reclassified 21\% (SHEA-IDSA 2010), 32\% (SHEA-IDSA 2018), or $46 \%$ (ESCMID) of CDI patients into the correct risk category. Consistent with our findings, Stevens et al. showed that both the SHEA-IDSA 2010 and 2018 criteria had low discrimination power $(c=0.582$ and 0.587$)$ [9]. Further evaluation of these clinical guidelines in high-quality studies is required, which is also suggested by the latest SHEA-IDSA guidelines [7].

Other severity indices did not evaluate their performance in predicting prolonged length of ICU stay separately from other outcomes, but they used composite measure of mortality, ICU admission, or colectomy [18, 27, 29]. However, ICU admission may not be a reasonable outcome measure because many patients with CDI are already in the ICU at the time of CDI occurrence. In our study, we assessed the secondary outcome of prolonged length of ICU stay following CDI and used 9 days as the cut-off. The 9-day cut-off is the 75th quartile in the distribution in our study population and is also comparable to the length of ICU stay attributable to CDI reported in two prior studies [30, 31]. Zahar et al's assessed the morbidity and mortality attributable to ICU-acquired CDI and estimated that the increase in the ICU stay due to CDI was $8.0 \pm 9.3$ days, in comparison to the diarrheic population [30]. Dodek et al. also investigated the attributable ICU and hospital length of stay of ICU-acquired CDI and reported that median ICU days following CDI was 7 days (IQR, 3-14 days) [31]. Therefore, an ICU stay of more than 9 days is a clinically relevant outcome measure for patients with CDI. In addition, our risk prediction model can better identity patients at high risk of prolonged ICU stay following CDI than can the guidelines.

Notably, we identified BUN-to-SCr ratio and serum glucose as strong predictors of 30-day mortality. A BUN-to-SCr ratio of $>20$ indicates dehydration and an early stage of kidney injury, which reasonably reflects the severity for CDI patients. In contrast, one previous study of 184 CDI patients did not find any association between a BUN-to-SCr ratio of $\geq 20$ and severe outcomes (defined as any event of ICU admission, colectomy, or death within 30 days) [29]. Moreover, no prior study has found an association between increased baseline glucose level and increased mortality among CDI patients. Our study showed that diabetes at admission was not associated with 30-day mortality, but a serum glucose level of $\geq 193 \mathrm{mg} / \mathrm{dL}$ was $(\mathrm{HR}=2.18 ; 95 \% \mathrm{CI}=$ $1.17,4.05)$. One study including 94 CDI patients identified that diabetes was associated with relapse of CDI (odds ratio $[\mathrm{OR}]=2.7 ; 95 \% \mathrm{CI}=0.8-9.2$ ) [32]. Another study including $247 \mathrm{CDI}$ patients revealed that diabetes was an independent risk factor for recurrent CDI within 6 months $(\mathrm{OR}=3.05 ; 95 \% \mathrm{CI}=1.84,5.03)$ but that serum glucose level was not (median of $147 \mathrm{mg} / \mathrm{dL}$ for recurrent
CDI and $146 \mathrm{mg} / \mathrm{dL}$ for nonrecurrent CDI) [33]. Blood glucose can influence the host immune-inflammatory response, such as macrophages, and affect the community structure of the gut microbiome, such as changing the ratio of nontoxigenic to toxigenic C. difficile [34]. Whether a hyperglycemic status in itself or through modification of a patient's intestinal microbiome facilitates the growth of $C$. difficile warrants further investigation [34]. Both BUN-to$\mathrm{SCr}$ ratio and serum glucose can be clinically modified and can serve as indicators to measure treatment optimization. Future research should clarify whether modifying these predictors can benefit patients with CDI.

Our study has several limitations. First, due to the retrospective design, the screening and diagnosis of CDI were not based on a standardized research protocol and certain variables of interest had missing values. However, we used extensive data-which were electronic medical records from the well-established CMUH-CRDR, expert adjudication of clinical presentation of CDI, and the National Cause of Death Dataset-, and multiple imputation method [21], to compensate for this limitation. Second, not all patients with CDI received molecular typing of $C$. difficile, which prevented us from differentiating toxigenic versus nontoxigenic strains for all CDI and evaluating the prognostic value of strain virulence. Nonetheless, our proposed risk model provides simple and readily available laboratory markers to triage patients with CDI and lower the action threshold to initiate optimization of fluid status and empirical antibiotic therapy.

\section{Conclusions}

Our proposed risk prediction model and scoring system performs more accurately in identifying potentially severe $\mathrm{CDI}$ than do existing guidelines. The newly identified clinical markers, namely BUN-to-SCr ratio and glucose, are readily available and also increase awareness of clinicians to optimize supportive care in patients with CDI. Future research should replicate our study in other populations. The infectious disease community should work toward consensus regarding the definition of severity and treatment response of CDI to support comparability of information and evidence-driven decision making for optimal CDI care.

\section{Supplementary information}

Supplementary information accompanies this paper at https://doi.org/10. 1186/s13756-019-0642-z.

Additional file 1. Supplementary method: Clostridium difficile testing; Figure S1. Time frames for the definition of covarieates; Table S1. Net reclassification of risk prediction score and the published guidelines.

\section{Abbreviations}

APACHE: Acute Physiology and Chronic Health Evaluation; BUN: Blood urea nitrogen; CDI: Clostridium difficile infection; Cl: Confidence interval; CMUH: China 
Medical University Hospital; CRDR: Clinical Research Data Repository; eGFR: estimated Glomerular filtration rate; ESCMID: The European Society of Clinical Microbiology and Infectious Diseases; HR: Hazard ratio; ICU: Intensive care unit; IQR: Interquartile range; NRI: Net reclassification index; SCr: Serum creatinine; SHEA-IDSA: The Society for Healthcare Epidemiology of America and The Infectious Diseases Society of America; WBC: White blood cell

\section{Acknowledgements}

Not applicable.

\section{Authors' contributions}

HYC designed the study, coordinated the data preparation, supervised the data analysis, and wrote a major part of this manuscript; $\mathrm{HCH}$ and CWC contributed to the data preparation and the data analysis; $Y C Y$ contributed to the quality check of the database; YCC reviewed the electronic medical records to abstract the data of diarrhea, ICU status, and APACHE II score; NT and HSL provided the data of $C$. difficile culture and toxin tests and the clinical microbiology information; MWH contributed to the study design and critically edited the manuscript; CCK supervised the whole study and critically edited the manuscript. All authors read and approved the final manuscript.

\section{Funding}

None of the authors received any funding to conduct this study.

\section{Availability of data and materials}

The minimal datasets generated and/or analysed during the current study are available from the corresponding author on reasonable request.

\section{Ethics approval and consent to participate}

The Institutional Review Board of CMUH approved this study (105-REC3-068 \& 107-REC2-016) and the need for informed consents was waived.

\section{Consent for publication}

Not applicable.

\section{Competing interests}

The authors declare that they have no competing interests.

\section{Author details}

'Big Data Center, China Medical University Hospital, Taichung 404, Taiwan. ${ }^{2}$ Department of Medical Research, Department of Internal Medicine, China Medical University Hospital, Taichung 404, Taiwan. ${ }^{3}$ Department of Laboratory Medicine, China Medical University Hospital, Taichung 404, Taiwan. ${ }^{4}$ Division of Infectious Diseases, Department of Internal Medicine, China Medical University Hospital, Taichung 404, Taiwan. ${ }^{5}$ Kidney Institute and Division of Nephrology, Department of Internal Medicine, China Medical University Hospital, Taichung 404, Taiwan.

Received: 9 May 2019 Accepted: 1 November 2019 Published online: 12 November 2019

\section{References}

1. McDonald LC, Owings M, Jernigan DB. Clostridium difficile infection in patients discharged from US short-stay hospitals, 1996-2003. Emerg Infect Dis. 2006;12(3):409-15.

2. Evans $C T$, Safdar N. Current trends in the epidemiology and outcomes of Clostridium difficile infection. Clin Infect Dis. 2015;60(Suppl 2):S66-71.

3. Centers for Disease Control and Prevention. Antibiotic Resistance Threats in the United States, 20132013 [Available from: https:/www.cdc.gov/ drugresistance/threat-report-2013/index.html.

4. Crowell KT, Julian KG, Katzman M, Berg AS, Tinsley A, Williams ED, et al. Compliance with Clostridium difficile treatment guidelines: effect on patient outcomes. Epidemiol Infect. 2017;145(11):2185-92.

5. Patel I, Wungjiranirun M, Theethira T, Villafuerte-Galvez J, Castillo N, Akbari $M$, et al. Lack of adherence to SHEA-IDSA treatment guidelines for Clostridium difficile infection is associated with increased mortality. J Antimicrob Chemother. 2017;72(2):574-81.

6. Cohen SH, Gerding DN, Johnson S, Kelly CP, Loo VG, McDonald LC, et al. Clinical practice guidelines for Clostridium difficile infection in adults: 2010 update by the society for healthcare epidemiology of America (SHEA) and the infectious diseases society of America (IDSA). Infect Control Hosp Epidemiol. 2010;31(5):431-55.

7. McDonald LC, Gerding DN, Johnson S, Bakken JS, Carroll KC, Coffin SE, et al. Clinical practice guidelines for Clostridium difficile infection in adults and children: 2017 update by the Infectious Diseases Society of America (IDSA) and Society for Healthcare Epidemiology of America (SHEA). Clin Infect Dis. 2018;66(7):987-94.

8. Debast SB, Bauer MP, Kuijper EJ. European Society of Clinical M, Infectious D. European Society of Clinical Microbiology and Infectious Diseases: update of the treatment guidance document for Clostridium difficile infection. Clin Microbiol Infect. 2014;20(Suppl 2):1-26.

9. Stevens VJ, Jones M, Nelson RE, Khader K, Samore M, Rubin M. 489. Validation of the SHEA/IDSA Severity Criteria to Predict Poor Outcomes Among Inpatients and Outpatients With Clostridium difficile Infection. Open Forum Infect Dis. 2018:5(Suppl 1):S181.

10. Welfare MR, Lalayiannis LC, Martin KE, Corbett S, Marshall B, Sarma JB. Comorbidities as predictors of mortality in Clostridium difficile infection and derivation of the ARC predictive score. J Hosp Infect. 2011;79(4):359-63.

11. Lungulescu OA, Cao W, Gatskevich E, Thabano L, Stratidis JG. CSI: a severity index for Clostridium difficile infection at the time of admission. J Hosp Infect. 2011;79(2):151-4.

12. Bhangu S, Bhangu A, Nightingale P, Michael A. Mortality and risk stratification in patients with Clostridium difficile-associated diarrhoea. Color Dis. 2010;12(3):241-6.

13. Zilberberg MD, Shorr AF, Micek ST, Doherty JA, Kollef MH. Clostridium difficile-associated disease and mortality among the elderly critically ill. Crit Care Med. 2009;37(9):2583-9.

14. Velazquez-Gomez IR-R, Rocha-Rodriguez R, Toro DH, Gutierrez-Nunez JJ, Gonzalez G, Saavedra S. A severity score index for Clostridium difficile infection. Infect Dis Clin Pract. 2008;16(6):376-8.

15. Miller MA, Louie T, Mullane K, Weiss K, Lentnek A, Golan Y, et al. Derivation and validation of a simple clinical bedside score (ATLAS) for Clostridium difficile infection which predicts response to therapy. BMC Infect Dis. 2013;13:148.

16. Hu MY, Katchar K, Kyne L, Maroo S, Tummala S, Dreisbach V, et al. Prospective derivation and validation of a clinical prediction rule for recurrent Clostridium difficile infection. Gastroenterology. 2009;136(4):1206-14.

17. Abou Chakra CN, Pepin J, Valiquette L. Prediction tools for unfavourable outcomes in Clostridium difficile infection: a systematic review. PLoS One. 2012;7(1):e30258.

18. Gujja D, Friedenberg FK. Predictors of serious complications due to Clostridium difficile infection. Aliment Pharmacol Ther. 2009;29(6):635-42.

19. Bauer MP, Hensgens MP, Miller MA, Gerding DN, Wilcox MH, Dale AP, et al. Renal failure and leukocytosis are predictors of a complicated course of Clostridium difficile infection if measured on day of diagnosis. Clin Infect Dis. 2012;55(Suppl 2):S149-53.

20. Levey AS, Stevens LA, Schmid CH, Zhang YL, Castro AF 3rd, Feldman HI, et al. A new equation to estimate glomerular filtration rate. Ann Intern Med. 2009;150(9):604-12.

21. Sterne JA, White IR, Carlin JB, Spratt M, Royston P, Kenward MG, et al. Multiple imputation for missing data in epidemiological and clinical research: potential and pitfalls. BMJ. 2009;338:b2393.

22. Harrell FE. The PHGLM procedure. In SUGI supplemental library guide, version 5 edition. Cary, NC: SAS Institute Inc; 1986.

23. Mehta HB, Mehta V, Girman CJ, Adhikari D, Johnson ML. Regression coefficient-based scoring system should be used to assign weights to the risk index. J Clin Epidemiol. 2016;79:22-8.

24. Alba AC, Agoritsas T, Walsh M, Hanna S, lorio A, Devereaux PJ, et al. Discrimination and calibration of clinical prediction models: Users' guides to the medical literature. JAMA. 2017;318(14):1377-84.

25. Borren NZ, Ghadermarzi S, Hutfless S, Ananthakrishnan AN. The emergence of Clostridium difficile infection in Asia: a systematic review and metaanalysis of incidence and impact. PLoS One. 2017;12(5):e0176797.

26. Zar FA, Bakkanagari SR, Moorthi KM, Davis MB. A comparison of vancomycin and metronidazole for the treatment of Clostridium difficile-associated diarrhea, stratified by disease severity. Clin Infect Dis. 2007:45(3):302-7.

27. Gomez-Simmonds A, Kubin CJ, Furuya EY. Comparison of 3 severity criteria for Clostridium difficile infection. Infect Control Hosp Epidemiol. 2014;35(2):196-9.

28. Hernandez-Garcia R, Garza-Gonzalez E, Miller M, Arteaga-Muller G. Galvan-de Ios Santos AM, Camacho-Ortiz a. application of the ATLAS score for evaluating the severity of Clostridium difficile infection in teaching hospitals in Mexico. Braz J Infect Dis. 2015;19(4):399-402. 
29. Fujitani S, George WL, Murthy AR. Comparison of clinical severity score indices for Clostridium difficile infection. Infect Control Hosp Epidemiol. 2011;32(3):220-8.

30. Zahar JR, Schwebel C, Adrie C, Garrouste-Orgeas M, Francais A, Vesin A, et al. Outcome of ICU patients with Clostridium difficile infection. Crit Care. 2012;16(6):R215.

31. Dodek PM, Norena M, Ayas NT, Romney M, Wong H. Length of stay and mortality due to Clostridium difficile infection acquired in the intensive care unit. J Crit Care. 2013;28(4):335-40.

32. Dial S, Alrasadi K, Manoukian C, Huang A, Menzies D. Risk of Clostridium difficile diarrhea among hospital inpatients prescribed proton pump inhibitors: cohort and case-control studies. CMAJ. 2004;171(1):33-8.

33. Shakov R, Salazar RS, Kagunye SK, Baddoura WJ, DeBari VA. Diabetes mellitus as a risk factor for recurrence of Clostridium difficile infection in the acute care hospital setting. Am J Infect Control. 2011;39(3):194-8.

34. Qu HQ, Jiang ZD. Clostridium difficile infection in diabetes. Diabetes Res Clin Pract. 2014;105(3):285-94.

\section{Publisher's Note}

Springer Nature remains neutral with regard to jurisdictional claims in published maps and institutional affiliations.

Ready to submit your research? Choose BMC and benefit from:

- fast, convenient online submission

- thorough peer review by experienced researchers in your field

- rapid publication on acceptance

- support for research data, including large and complex data types

- gold Open Access which fosters wider collaboration and increased citations

- maximum visibility for your research: over $100 \mathrm{M}$ website views per year

At $\mathrm{BMC}$, research is always in progress.

Learn more biomedcentral.com/submissions 